Arq. Bras. Med. Vet. Zootec., v.64, n.3, p.606-614, 2012

\title{
Efeito da administração pré-natal da dexametasona em ratas sobre os perfis glicídicos e hematológicos materno e da prole
}

[Effect of prenatal administration of dexamethasone in rats on profiles hematologic and glicidic maternal and offspring]

P.E.A. Vilaça-Junior, A.F. Soares, V. Wanderley-Teixeira, A.C.C. Araújo, A.A.C. Teixeira*

Universidade Federal Rural de Pernambuco - UFRPE - Recife, PE

\section{RESUMO}

Avaliou-se o efeito da administração de dexametasona no início e no meio da gestação de ratas, sobre os perfis glicídicos e hematológicos materno e da prole. Os animais foram submetidos aos seguintes tratamentos: dexametasona do primeiro ao sétimo dia e placebo do oitavo ao $14^{\circ}$ dia; placebo do primeiro ao sétimo dia e dexametasona do oitavo ao $14^{\mathrm{o}}$ dia; dexametasona do primeiro ao $14^{\circ}$ dia e placebo do primeiro ao $14^{\circ}$ dia de gestação. A dexametasona foi administrada por via intraperitoneal, na dose de $0,8 \mathrm{mg} / \mathrm{kg}$. Foram coletadas amostras de sangue no sétimo, $14^{\circ}$ e $21^{\circ}$ dias de gestação, e de sangue e tecido hepático da prole no quinto, $10^{\circ}$ e $15^{\circ}$ dias pós-natal. Para a verificação das reservas de glicogênio hepático da prole, cortes histológicos foram corados pelo ácido periódico de Schiff. Os resultados apontam para um efeito tempo-dependente da administração de dexametasona durante a gestação, levando a alterações temporais distintas na hematologia e na concentração plasmática de carboidratos nas matrizes e na prole.

Palavras-chave: rato, dexametasona, características hematológicas, carboidratos, fígado

\begin{abstract}
The effect of the administration of dexamethasone at the beginning and middle of the pregnancy in rats on hematological and glicidic maternal and offspring profile was evaluated. The animals underwent the following treatments: dexamethasone from the first to the seventh day and placebo from the 8th to the 14 th day, placebo from the first to the seventh day and dexamethasone from the 8th to the 14th day; dexamethasone from the 1st to the 14th day, and placebo treatment from the first to the 14th day of gestation. Dexamethasone was administered intraperitoneally at a dose of $0.8 \mathrm{mg} / \mathrm{kg}$. Blood samples were collected on the 7th, 14th and 21st days of pregnancy, and blood and liver tissue of offspring on the fifth, 10 th and 15th days postnatal. For verification of the reserves of liver glycogen on the offspring, histological sections were stained with periodic acid-Schiff. The results point to a time-dependent effect of dexamethasone during pregnancy, leading to different temporal changes in hematology and plasma levels of carbohydrates in headquarters and in the offspring.
\end{abstract}

Keywords: rat, dexamethasone, hematologic parameters, carbohydrates, liver

\section{INTRODUÇÃO}

Os glicocorticoides possuem atividade antiinflamatória e imunossupressora, porém é notória sua interferência no metabolismo de carboidratos e de proteínas. Ainda assim, esses fármacos estão entre os grupos de medicamentos usados com maior frequência na veterinária no tratamento de

Recebido em 19 de setembro de 2011

Aceito em 31 de janeiro de 2012

*Autor para correspondência (corresponding author)

E-mail: alvaro@dmfa.ufrpe.br diversas condições clínicas de desordens inflamatórias, alérgicas e imunomediadas (Rosa et al., 2003). Em seres humanos são utilizados também em aplicações pré-natais para promover a maturação pulmonar fetal em gestantes com risco de parto prematuro, evitando a síndrome do desconforto respiratório, as hemorragias peri e intraventricular e a mortalidade neonatal (Meneguel et al., 2002). 
Dentre os glicocorticoides sintéticos, a dexametasona é largamente utilizada por apresentar efeitos análogos ao da cortisona (Sloboda et al., 2005). Durante a gestação, o transporte transplacentário de glicocorticoides é regulado pelas enzimas $11 \beta$-hidroxiesteroide desidrogenase (11ß-HSD) tipo 1 e 2 , que atuam na reativação e inativação de glicocorticoides, respectivamente, regulando a exposição do feto a esses fármacos (Diederich et al., 2002). Devido à progressiva redução da bioatividade da enzima $11 \beta$-HSD2 ao longo da gestação (Waddell et al., 1998), o terço final é o período de gestação em que ocorre maior permissibilidade do tráfego de glicocorticoides, levando a alterações fisiológicas, como a elevação do nível glicêmico pós-natal, a redução da síntese de receptores para insulina e a mobilização de glicogênio para a corrente sanguínea (Nyirenda et al., 1998).

Além das alterações relacionadas com a bioquímica do sangue, a dexametasona exerce influência sobre a distribuição de células sanguíneas por meio da inibição da expressão de citocinas (Haynesworth et al., 1996), da supressão de fatores de proliferação de linfócitos (Almawi et al., 1991) e da indução da apoptose (Mor e Cohen, 1996). Dentre as alterações verificadas na distribuição de leucócitos, estão a redução drástica do número de linfócitos $\mathrm{T}$ e $\mathrm{B}$, e de células NK (natural killer), além do aumento de neutrófilos (Dhabhar et al., 1996).

A terapia com glicocorticoides pode prover um benefício de curto prazo. Contudo, pode levar a consequências de longo prazo, como a programação de níveis elevados de glicocorticoides promovendo elevação da pressão sanguínea, hiperglicemia e todo tipo de resposta gerada de maneira semelhante àquelas encontradas no estresse, atingindo níveis patológicos na vida adulta (Brown et al., 1996). Assim, o presente estudo testou a hipótese de que a administração da dexametasona nos dois terços iniciais da gestação pode interferir nos perfis hematológicos e glicídicos materno e da prole.

\section{MATERIAL E MÉTODOS}

Foram utilizadas 24 ratas albinas (Rattus norvergicus albinus) da linhagem Wistar, procedentes de biotério. $\mathrm{O}$ protocolo experimental foi aprovado pela Comissão de Ética institucional, de $n^{\circ}$. 23082.010750/2010.
As fêmeas foram distribuídas ao acaso, em quatro grupos: GI, formado por ratas tratadas do primeiro ao sétimo dia de gestação com dexametasona e do oitavo ao $14^{\underline{0}}$ dia com placebo; GII, formado por ratas tratadas do primeiro ao sétimo dia de gestação com placebo e do oitavo ao $14^{\circ}$ dia com dexametasona; GIII, formado por ratas prenhas tratadas com dexametasona do primeiro ao $14^{\circ}$ dia de gestação com redução progressiva da dose de dexametasona em $15 \%$ a cada dois dias (desmame); e GIV, formado por ratas prenhes tratadas com placebo do primeiro ao $14^{\circ}$ dia de gestação. Como placebo e para a diluição progressiva da dexametasona, foi utilizada solução salina em $\mathrm{pH}$ fisiológico. Foi utilizada a formulação comercial Decadron ${ }^{\circledR}$ (fosfato dissódico de dexametasona), administrada por via intraperitoneal, na dose de $0,8 \mathrm{mg} / \mathrm{kg}$ (VilaçaJúnior et al., 2008).

O sangue foi coletado por punção da veia caudal lateral com uso de cateter (24G) no sétimo, $14^{\circ} \mathrm{e}$ $21^{0}$ dias de gestação. Após centrifugação, o plasma foi acondicionado à temperatura de $20^{\circ} \mathrm{C}$, para análises posteriores. O sangue dos filhotes foi coletado por punção cardíaca no quinto, $10^{\circ}$ e $15^{\circ}$ dias após o nascimento, sob anestesia com pentobarbital na dosagem de $40 \mathrm{mg} / \mathrm{kg}$, intraperitoneal (Penicaud et al., 1987). Para cada intervalo de coleta foram escolhidos aleatoriamente 10 filhotes por grupo experimental. $\mathrm{O}$ plasma foi acondicionado nas mesmas condições do plasma materno.

Para o hematócrito, alíquotas de sangue total foram coletadas em capilares heparinizados e centrifugadas por cinco minutos à velocidade de 7000rpm. Na contagem total de hemácias, as alíquotas foram diluídas em solução de Hayem na proporção de 1:400 e contadas em câmara de Neubauer. Os resultados foram submetidos à fórmula: $\mathrm{Hm} \times 10$ × 400 × $5=\mathrm{Hm} / \mu \mathrm{L}$, em que: Hm é o número total de hemácias contadas, 10 é o fator de conservação para o volume de $1 \mathrm{~mm}^{3}$ (profundidade da câmara de Neubauer), 400 é o fator da conservação da diluição utilizada, e 5 é o fator de conservação para área de $1 \mathrm{~mm}^{2}$ (5 de 25 quadrados médios), sendo o resultado expresso como o número de hemácias/ $\mu \mathrm{L}$. Para a contagem total de leucócitos, as alíquotas foram diluídas em solução de Turk na proporção de 1:20. Os resultados foram submetidos à fórmula: Lc $\times 20 \times 10 / 4=\mathrm{Lc} / \mu \mathrm{L}$, em que: Lc é o número 
total de leucócitos contados, 10 é o fator de conservação para o volume de $1 \mathrm{~mm}^{3}$ (profundidade da lâmina da câmara de Neubauer), 20 é o fator de conservação da diluição utilizada e 4 é o fator de conservação para a área de $1 \mathrm{~mm}^{2}$ (número de quadrados), sendo o resultado expresso como o número de leucócitos $/ \mu \mathrm{L}$. Para contagem diferencial de leucócitos, foram confeccionados esfregaços de sangue total corados pelo método de panótico rápido.

Para análise de carboidratos totais, seguiu-se o protocolo descrito por Laurentini e Edwards (2003), para leitura em microplaca (Anthos 2010 Microplate Absorbance Reader, Biochrom Ltd, Cambridge, UK). Todas as análises hematológicas e as dosagens de carboidratos foram realizadas em triplicata.

Fragmentos do fígado da prole foram fixados em líquido de Boüin por 48 horas, incluídos em parafina, e os cortes corados pelo ácido periódico de Schiff (PAS) para análise histoquímica de glicogênio. Os cortes foram analisados em microscópio Olympus ${ }^{\circledR}$ Bx50. Os dados das análises hematológicas e dosagens de carboidratos totais foram submetidos ao teste não paramétrico de Kruskal-Wallis, em que as médias foram comparadas pelo teste de Wilcoxon-Mann-Whitney $(\mathrm{P}<0,05)$.

\section{RESULTADOS}

Verificou-se que, no sétimo dia de gestação, houve redução significativa do volume de hematócrito e do número total de leucócitos nas fêmeas dos grupos I e III. Na contagem diferencial, evidenciou-se uma neutrofilia associada com linfopenia e eosinopenia (Tab. 1). Aos 14 dias de gestação, houve uma redução significativa do volume de hematócrito apenas no grupo III. Com relação ao número de leucócitos e à contagem diferencial, os resultados foram semelhantes aos observados nas fêmeas com sete dias de gestação para os grupos II e III. No entanto, verificou-se, nesse período, redução significativa no número total de hemácias nos animais dos grupos I, II e III em relação aos do grupo IV (Tab. 2). No terço final da gestação, as fêmeas apresentaram redução dos valores de hematócrito, neutrofilia, linfopenia e eosinopenia apenas no grupo III. O número total de hemácias e leucócitos permaneceu reduzido apenas nos grupos II e III (Tab. 3). Os dados dos parâmetros sanguíneos dos filhotes com 10 e 15 dias de nascidos constam nas Tab. 4 e 5, respectivamente. Com 10 dias de idade, os filhotes não apresentaram alteração nos valores de hematócrito, porém um aumento significativo foi observado no número total de hemácias no grupo III. Nos parâmetros contagem total e diferencial dos leucócitos, esses filhotes mostraram o mesmo perfil evidenciado nas suas matrizes durante toda a gestação (Tab. 4). Não houve variação significativa nas características analisadas para os filhotes com 15 dias de nascido (Tab. 5).

A concentração sérica de carboidratos totais nas matrizes aos sete dias de gestação variou bastante entre os grupos experimentais, independentemente do tratamento, porém houve aumento significativo nas matrizes do grupo III em relação às dos grupos I e IV. Com 14 dias de gestação, houve redução significativa da concentração de carboidratos totais nas matrizes do grupo III em relação às do grupo IV. Já aos 21 dias de gestação, a concentração de carboidratos totais foi similar entre os grupos (Fig. 1). Nos filhotes com cinco dias de vida, a concentração sérica de carboidratos totais foi menor nos grupos tratados com dexametasona em relação ao grupo tratado com placebo, o qual diferiu estatisticamente dos grupos I e III. No $10^{\circ}$ dia de vida, só foram observadas diferenças significativas entre os grupos III e IV. Não foram verificadas variações significativas na concentração sérica de carboidratos totais para os filhotes com 15 dias de vida (Fig. 2). A análise histoquímica do fígado pelo ácido periódico de Schiff apresentou reação de intensidade variada apenas nos filhotes com 10 dias de idade, sendo mais intensa nos ratos dos grupos I e IV, em relação aos dos grupos II e III (Fig. 3).

\section{DISCUSSÃO}

Os glicocorticoides exercem efeitos sobre o mecanismo de homeostase dos fluidos corporais, provocando alterações como redução da volemia e aumento da osmolalidade do sangue (Ruginsk et al., 2007). Sabe-se ainda que os valores de hematócrito estão relacionados à capacidade de transporte de oxigênio, à viscosidade do sangue e à eficiência de fluxo microcirculatório nos tecidos (Isbister, 1997). Portanto, a redução significativa desse parâmetro pode acarretar 
possível prejuízo dessas funções, desencadeando alterações no transporte de oxigênio transplacentário e no suprimento de nutrientes ao feto, o que comprometeria o desenvolvimento fetal (Jansson e Powell, 2006). Alterações no volume do hematócrito foram verificadas no sétimo dia de gestação nos grupos I e III, e no $14^{\circ}$ dia de gestação no grupo III em relação ao grupo IV, porém sem representar prejuízo para o feto, pois nenhuma alteração significativa para essa característica foi encontrada nos filhotes no $10^{\circ}$ e $15^{\circ}$ dias pós-natal.

A administração de dexametasona induz à redução da síntese de eritropoetina e, consequentemente, à eritropoese (Giglio et al., 1981). Neste experimento, houve redução do número de hemácias nas ratas progenitoras, em relação ao grupo IV, nos grupos I, II e III, no $14^{\circ}$ dia de gestação, e nos grupos II e III, no $21^{\circ}$ dia de gestação, indicando ação similar da dexametasona sobre a eritropoese independentemente do período de aplicação. $\mathrm{O}$ restabelecimento no número de hemácias do grupo I para valores similares aos encontrados no grupo IV, aos 21 dias de gestação, mostra que a redução não perdura até o fim da gestação quando administrada apenas no terço inicial da gestação. Com relação à prole, sabe-se que a eritropoese fetal nos dois terços iniciais da gestação é realizada pelo tecido hepático (Isern et al., 2008) e que a regulação dessa função é realizada pelo nível de glicocorticoides circulantes (Bauer et al., 1999). A elevação significativa de eritrócitos verificada nos filhotes do grupo III no $10^{\underline{0}}$ dia pós-natal sugere o estabelecimento de uma relação tempodependente devido à administração prolongada da dexametasona, mesmo tendo sido realizado o desmame.

A característica imunossupressora dos glicocorticoides (Faas et al., 2000) pode ter sido responsável pela redução do número de leucócitos observado nas ratas progenitoras no sétimo dia de gestação nos grupos I e III, e no $14^{\circ}$ e $21^{\circ}$ dias de gestação nos grupos II e III. Esses dados revelam que tanto a administração contínua quanto aquela a partir da segunda semana de gestação mantiveram um efeito imunossupressor até o final da gestação. Durante a gestação, ocorre alteração na composição prioritária de células do sistema imunológico no sangue periférico, mudando-a de resposta de celular para humoral (Veenstra Van Nieuwenhoven et al., 2002). A liberação de glicocorticoides endógenos na corrente sanguínea está associada à redução do número de linfócitos e eosinófilos, além do aumento no número de neutrófilos (Dhabhar et al., 1995), sendo a intensidade e a duração da estimulação do agente estressor determinantes para a configuração das alterações nessas populações celulares (Dhabhar e Mcewen, 1997). Dessa forma, justificam-se as alterações encontradas, como a neutrofilia, linfopenia e a eosinopenia, em decorrência da ação dos glicocorticoides, sendo os efeitos encontrados relacionados de forma tempo-dependente, mostrando maior significância para o grupo III, em que a exposição à dexametasona foi maior que nos outros grupos.

Tabela 1. Médias de hematócrito, contagem total e diferencial das células sanguíneas das ratas com 7 dias de gestação

\begin{tabular}{lccccc}
\hline Grupos & I & II & III & IV & P \\
\hline Ht $(\%)$ & $44,66 \pm 3,51 \mathrm{~b}$ & $51,00 \pm 1,00 \mathrm{a}$ & $42,66 \pm 2,08 \mathrm{~b}$ & $52,66 \pm 3,78 \mathrm{a}$ & 0,0066 \\
$\mathrm{RBC}\left(10^{6} / \mu \mathrm{L}\right)$ & $7,20 \pm 0,14 \mathrm{a}$ & $7,08 \pm 0,08 \mathrm{a}$ & $7,15 \pm 0,10 \mathrm{a}$ & $6,87 \pm 0,17 \mathrm{a}$ & 0,8229 \\
WBC $\left(10^{3} / \mu \mathrm{L}\right)$ & $5,05 \pm 0,20 \mathrm{~b}$ & $10,00 \pm 0,19 \mathrm{a}$ & $4,66 \pm 0,25 \mathrm{~b}$ & $10,38 \pm 0,20 \mathrm{a}$ & 0,0042 \\
Linfócitos $(\%)$ & $30,22 \pm 3,08 \mathrm{~b}$ & $45,77 \pm 2,15 \mathrm{a}$ & $27,66 \pm 5,81 \mathrm{~b}$ & $45,55 \pm 3,37 \mathrm{a}$ & 0,0335 \\
Neutrófilos $(\%)$ & $73,66 \pm 2,36 \mathrm{a}$ & $47,33 \pm 4,84 \mathrm{~b}$ & $75,00 \pm 1,62 \mathrm{a}$ & $50,35 \pm 5,27 \mathrm{~b}$ & 0,0176 \\
Eosinófilos $(\%)$ & $1,44 \pm 0,18 \mathrm{~b}$ & $2,77 \pm 0,50 \mathrm{a}$ & $1,11 \pm 0,67 \mathrm{~b}$ & $2,78 \pm 0,38 \mathrm{a}$ & 0,0084 \\
Monócitos $(\%)$ & $3,44 \pm 1,59 \mathrm{a}$ & $3,11 \pm 0,88 \mathrm{a}$ & $3,00 \pm 1,90 \mathrm{a}$ & $4,01 \pm 2,05 \mathrm{a}$ & 0,1679 \\
Basófilos $(\%)$ & $0,85 \pm 071 \mathrm{a}$ & $1,00 \pm 0,91 \mathrm{a}$ & $1,22 \pm 0,76 \mathrm{a}$ & $1,55 \pm 1,00 \mathrm{a}$ & 0,0609
\end{tabular}

Médias seguidas por letras distintas na linha diferem significativamente entre si pelo teste de Wilcoxon-MannWhitney $(\mathrm{P}<0,05)$. 
Tabela 2. Médias de hematócrito, contagem total e diferencial das células sanguíneas das ratas com 14 dias de gestação

\begin{tabular}{lccccc}
\hline Grupos & I & II & III & IV & P \\
\hline Ht $(\%)$ & $47,67 \pm 2,88 \mathrm{a}$ & $44,34 \pm 2,08 \mathrm{a}$ & $40,33 \pm 1,52 \mathrm{~b}$ & $48,33 \pm 1,38 \mathrm{a}$ & 0,0055 \\
$\mathrm{RBC}\left(10^{6} / \mu \mathrm{L}\right)$ & $7,10 \pm 0,13 \mathrm{~b}$ & $6,98 \pm 0,08 \mathrm{~b}$ & $7,02 \pm 0,11 \mathrm{~b}$ & $8,03 \pm 0,07 \mathrm{a}$ & 0,0472 \\
WBC $\left(10^{3} / \mu \mathrm{L}\right)$ & $11,93 \pm 0,27 \mathrm{a}$ & $4,88 \pm 0,24 \mathrm{~b}$ & $4,68 \pm 1,53 \mathrm{~b}$ & $12,00 \pm 0,34 \mathrm{a}$ & 0,0037 \\
Linfócitos $(\%)$ & $48,11 \pm 6,16 \mathrm{a}$ & $15,11 \pm 8,04 \mathrm{~b}$ & $25,77 \pm 5,55 \mathrm{~b}$ & $56,22 \pm 8,79 \mathrm{a}$ & 0,0004 \\
Neutrófilos $(\%)$ & $46,55 \pm 4,91 \mathrm{~b}$ & $79,11 \pm 7,41 \mathrm{a}$ & $66,66 \pm 5,20 \mathrm{a}$ & $53,11 \pm 3,65 \mathrm{~b}$ & 0,0033 \\
Eosinófilos $(\%)$ & $2.40 \pm 0,35 \mathrm{a}$ & $0,66 \pm 0,33 \mathrm{~b}$ & $0,77 \pm 0,83 \mathrm{~b}$ & $2,22 \pm 0,19 \mathrm{a}$ & 0,0037 \\
Monócitos $(\%)$ & $3,11 \pm 2,08 \mathrm{a}$ & $1,44 \pm 0,76 \mathrm{a}$ & $2,86 \pm 1,87 \mathrm{a}$ & $3,88 \pm 2,72 \mathrm{a}$ & 0,1372 \\
Basófilos $(\%)$ & $1,11 \pm 0,79 \mathrm{a}$ & $1,77 \pm 0,91 \mathrm{a}$ & $2,88 \pm 1,03 \mathrm{a}$ & $1,33 \pm 0,57 \mathrm{a}$ & 0,4012 \\
\hline
\end{tabular}

Médias seguidas por letras distintas na linha diferem entre si pelo teste de Wilcoxon-Mann-Whitney $(\mathrm{P}<0,05)$.

Tabela 3. Médias do hematócrito, contagem total e diferencial das células sanguíneas das ratas com 21 dias de gestação

\begin{tabular}{lccccc}
\hline Grupos & I & II & III & IV & P \\
\hline Ht $(\%)$ & $42,34 \pm 2,18 \mathrm{a}$ & $40,67 \pm 1,05 \mathrm{a}$ & $39,00 \pm 0,59 \mathrm{~b}$ & $46,00 \pm 5,21 \mathrm{a}$ & 0,0299 \\
$\mathrm{RBC}\left(10^{6} / \mu \mathrm{L}\right)$ & $8,02 \pm 0,09 \mathrm{a}$ & $7,95 \pm 0,04 \mathrm{~b}$ & $7,68 \pm 0,11 \mathrm{~b}$ & $8,14 \pm 0,10 \mathrm{a}$ & 0,0472 \\
WBC $\left(10^{3} / \mu \mathrm{L}\right)$ & $13,15 \pm 0,12 \mathrm{a}$ & $8,21 \pm 0,05 \mathrm{~b}$ & $7,97 \pm 2,39 \mathrm{~b}$ & $13,32 \pm 0,15 \mathrm{a}$ & 0,0193 \\
Linfócitos $(\%)$ & $34,88 \pm 4,35 \mathrm{a}$ & $29,66 \pm 5,22 \mathrm{a}$ & $20,57 \pm 3,21 \mathrm{~b}$ & $35,11 \pm 3,35 \mathrm{a}$ & 0,0301 \\
Neutrófilos $(\%)$ & $40,22 \pm 5,65 \mathrm{~b}$ & $53,11 \pm 5,24 \mathrm{~b}$ & $66,22 \pm 5,16 \mathrm{a}$ & $51,88 \pm 4,99 \mathrm{~b}$ & 0,0351 \\
Eosinófilos $(\%)$ & $2,33 \pm 0,89 \mathrm{a}$ & $2,11 \pm 0,50 \mathrm{a}$ & $0,97 \pm 0,16 \mathrm{~b}$ & $2,44 \pm 1,10 \mathrm{a}$ & 0,0211 \\
Monócitos $(\%)$ & $2,88 \pm 2,01 \mathrm{a}$ & $1,77 \pm 1,21 \mathrm{a}$ & $3,33 \pm 1,46 \mathrm{a}$ & $2,67 \pm 1,68 \mathrm{a}$ & 0,5127 \\
Basófilos $(\%)$ & $0,77 \pm 0,52 \mathrm{a}$ & $0,88 \pm 0,22 \mathrm{a}$ & $1,14 \pm 0,71 \mathrm{a}$ & $1,44 \pm 0,74 \mathrm{a}$ & 0,0632 \\
\hline
\end{tabular}

Médias seguidas por letras distintas na linha diferem entre si pelo teste de Wilcoxon-Mann-Whitney $(\mathrm{P}<0,05)$.

Tabela 4. Médias do hematócrito, contagem total e diferencial das células sanguíneas dos filhotes com 10 dias de nascidos

\begin{tabular}{lccccc}
\hline Grupos & I & II & III & IV & P \\
\hline Ht $(\%)$ & $27,77 \pm 4,62 \mathrm{a}$ & $26,99 \pm 2,33 \mathrm{a}$ & $30,21 \pm 0,50 \mathrm{a}$ & $26,33 \pm 3,60 \mathrm{a}$ & 0,4987 \\
RBC $\left(10^{6} / \mu \mathrm{L}\right)$ & $3,41 \pm 0,17 \mathrm{~b}$ & $3,53 \pm 0,14 \mathrm{~b}$ & $3,87 \pm 0,08 \mathrm{a}$ & $3,39 \pm 0,12 \mathrm{~b}$ & 0,8620 \\
WBC $\left(10^{3} / \mu \mathrm{L}\right)$ & $1,91 \pm 0,10 \mathrm{a}$ & $1,73 \pm 0,24 \mathrm{a}$ & $1,31 \pm 0,11 \mathrm{~b}$ & $2,02 \pm 0,20 \mathrm{a}$ & 0,0101 \\
Linfócitos $(\%)$ & $64,77 \pm 5,96 \mathrm{a}$ & $60,00 \pm 5,48 \mathrm{a}$ & $49,22 \pm 6,62 \mathrm{~b}$ & $62,33 \pm 5,13 \mathrm{a}$ & 0,0142 \\
Neutrófilos $(\%)$ & $23,55 \pm 6,17 \mathrm{~b}$ & $22,55 \pm 5,82 \mathrm{~b}$ & $36,77 \pm 4,02 \mathrm{a}$ & $21,66 \pm 3,11 \mathrm{~b}$ & 0,0087 \\
Eosinófilos $(\%)$ & $0,44 \pm 0,08 \mathrm{a}$ & $0,51 \pm 0,19 \mathrm{a}$ & $0,21 \pm 0,11 \mathrm{~b}$ & $1,44 \pm 1,03 \mathrm{a}$ & 0,0245 \\
Monócitos $(\%)$ & $6,77 \pm 5,96 \mathrm{a}$ & $8,46 \pm 2,93 \mathrm{a}$ & $7,88 \pm 1,26 \mathrm{a}$ & $8,07 \pm 1,84 \mathrm{a}$ & 0,1098 \\
Basófilos $(\%)$ & $4,44 \pm 2,10 \mathrm{a}$ & $3,78 \pm 0,78 \mathrm{a}$ & $2,97 \pm 0,85 \mathrm{a}$ & $3,56 \pm 0,62 \mathrm{a}$ & 0,2011 \\
\hline
\end{tabular}

Médias seguidas por letras distintas na linha diferem entre si pelo teste de Wilcoxon-Mann-Whitney $(\mathrm{P}<0,05)$.

Tabela 5. Médias de hematócrito, contagem total e diferencial das células sanguíneas dos filhotes com 15 dias de nascidos

\begin{tabular}{lccccc}
\hline Grupos & I & II & III & IV & P \\
\hline Ht $(\%)$ & $34,00 \pm 7,93 \mathrm{a}$ & $35,66 \pm 2,51 \mathrm{a}$ & $32,78 \pm 4,29 \mathrm{a}$ & $37,06 \pm 3,51 \mathrm{a}$ & 0,3543 \\
$\mathrm{RBC}\left(10^{6} / \mu \mathrm{L}\right)$ & $4,54 \pm 0,18 \mathrm{a}$ & $4,38 \pm 0,12 \mathrm{a}$ & $4,64 \pm 0,17 \mathrm{a}$ & $4,6 \pm 0,12 \mathrm{a}$ & 0,6324 \\
WBC $\left(10^{3} / \mu \mathrm{L}\right)$ & $2,33 \pm 0,35 \mathrm{a}$ & $2,40 \pm 0,25 \mathrm{a}$ & $2,03 \pm 0,34 \mathrm{a}$ & $2,11 \pm 0,22 \mathrm{a}$ & 0,3108 \\
Linfócitos $(\%)$ & $65,22 \pm 4,84 \mathrm{a}$ & $67,32 \pm 5,90 \mathrm{a}$ & $63,66 \pm 2,54 \mathrm{a}$ & $62,44 \pm 3,17 \mathrm{a}$ & 0,4111 \\
Neutrófilos $(\%)$ & $25,66 \pm 1,52 \mathrm{a}$ & $24,19 \pm 2,01 \mathrm{a}$ & $22,67 \pm 3,20 \mathrm{a}$ & $23,78 \pm 3,11 \mathrm{a}$ & 0,2493 \\
Eosinófilos $(\%)$ & $1,00 \pm 0,88 \mathrm{a}$ & $0,98 \pm 0,38 \mathrm{a}$ & $0,72 \pm 0,54 \mathrm{a}$ & $1,21 \pm 0,33 \mathrm{a}$ & 0,0733 \\
Monócitos $(\%)$ & $7,44 \pm 1,84 \mathrm{a}$ & $6,09 \pm 1,56 \mathrm{a}$ & $7,23 \pm 1,22 \mathrm{a}$ & $8,77 \pm 2,06 \mathrm{a}$ & 0,0509 \\
Basófilos $(\%)$ & $2,88 \pm 0,96 \mathrm{a}$ & $2,15 \pm 0,65 \mathrm{a}$ & $1,79 \pm 0,32 \mathrm{a}$ & $2,63 \pm 0,72 \mathrm{a}$ & 0,0635 \\
\hline
\end{tabular}

Médias seguidas por letras distintas na linha diferem entre si pelo teste de Wilcoxon-Mann-Whitney $(\mathrm{P}<0,05)$. 
Efeito da administração...

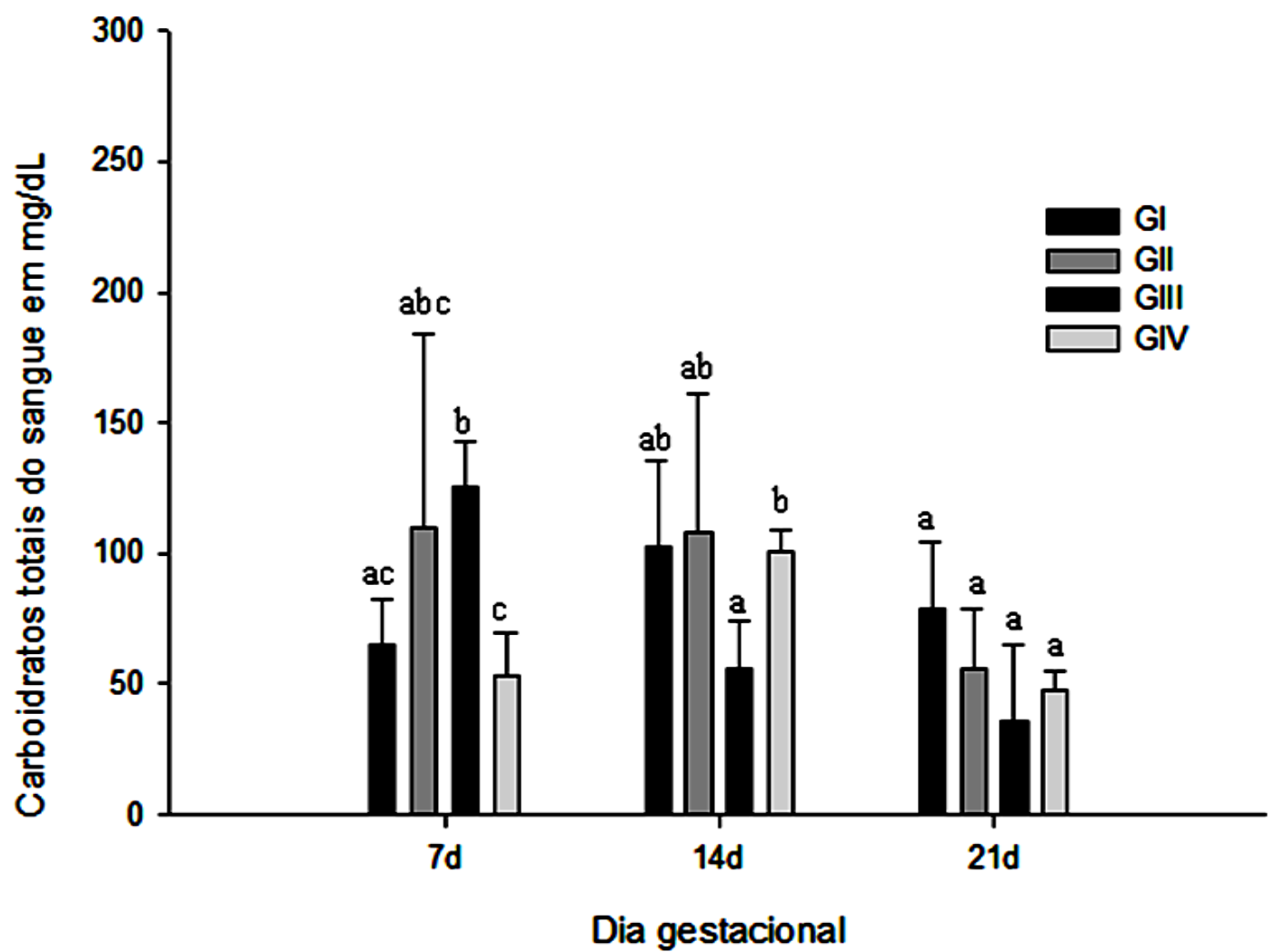

Figura 1. Concentração de carboidratos totais nas matrizes no sétimo, $14^{\circ}$ e $21^{\circ}$ dias de gestação. Médias seguidas por letras distintas em cada dia analisado diferem entre si pelo teste de Wilcoxon-Mann-Whitney $(\mathrm{P}<0,05)$.

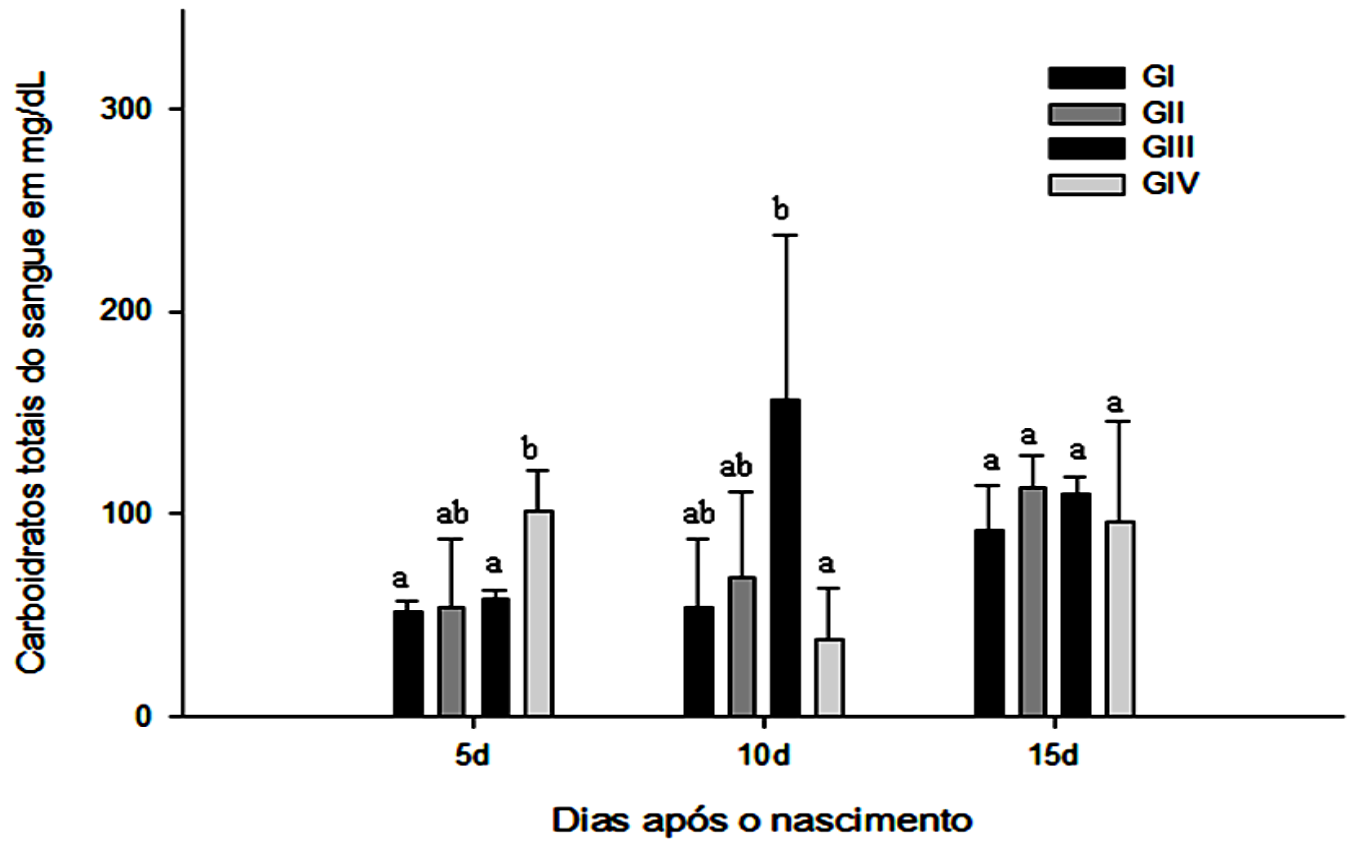

Figura 2. Concentração de carboidratos totais na prole, aos cinco, 10 e 15 dias de idade. Médias seguidas por letras distintas em cada dia analisado diferem entre si pelo teste de Wilcoxon-Mann-Whitney $(\mathrm{P}<0,05)$. 


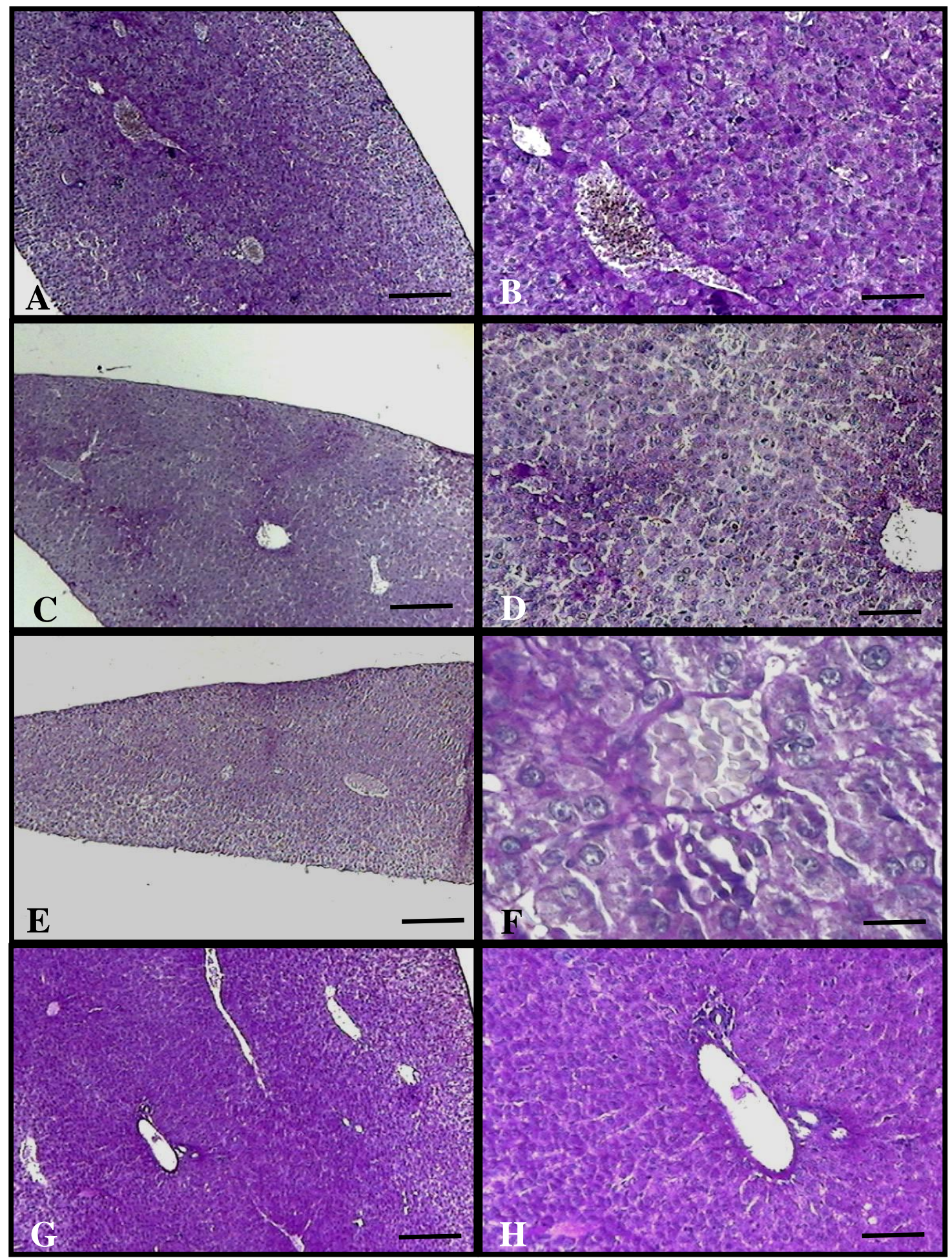

Figura 3. Fígado dos filhotes com 10 dias de idade. Observar variação na intensidade de coloração pelo P.A.S. nos grupos experimentais. A e B - grupo I; C e D - grupo II; E e F - grupo III; e G e H - grupo IV. Barra $=100 \mu \mathrm{m}(\mathrm{A}, \mathrm{C}, \mathrm{E}$ e G); Barra $=25 \mu \mathrm{m}(\mathrm{B}, \mathrm{D}, \mathrm{F}$ e H). 
A concentração sérica de carboidratos nas ratas progenitoras no sétimo dia de gestação variou independentemente do tratamento ou não com a dexametasona. Essa variação pode estar relacionada ao fato de que, durante a gestação, ocorrem adaptações no metabolismo de carboidratos, culminando com um progressivo estado de resistência à insulina, as quais impedem a metabolização de carboidratos totais maternos (Holness e Sugden, 1997). O desenvolvimento da resistência à insulina materna promove o aumento de carboidratos totais no início da gestação (Ericsson et al., 2007); por outro lado, a administração de dexametasona durante o terço final da gestação, do $14^{\underline{0}}$ ao $19^{-}$dia, estimula a secreção de insulina (hiperinsulemia), suprimindo a produção endógena de carboidratos totais, o que leva à redução da concentração sérica, sendo esse mecanismo ainda desconhecido (Holness e Sugden, 2001). Tal efeito foi observado nas fêmeas tratadas com dexametasona até o $14^{\circ}$ dia de gestação, mostrando uma relação tempodependente para o estabelecimento de um quadro de hiperglicemia associada à corticoterapia. O restabelecimento e a manutenção da concentração normal de carboidratos totais no sangue ocorrem no final da gestação, o que provavelmente aconteceu no $21^{\circ}$ dia de gestação (Kahn et al., 2001).

A análise da concentração de carboidratos totais nos filhotes mostrou redução aos cinco dias de vida nos grupos tratados com dexametasona. Porém, aos 10 dias de idade, apenas os filhotes nascidos das fêmeas tratadas por 14 dias apresentaram aumento significativo da concentração sérica de carboidratos totais em relação aos das ratas do grupo-controle. Isto pode estar relacionado ao potencial da dexametasona em induzir o desenvolvimento da resistência insulina em ratos jovens (Nyirenda et al., 1998), pois, nos primeios dias de vida, a glicemia em ratos sofre grandes variações, em parte atribuídas a alterações abruptas no teor de enzimas responsáveis pela disponibilização da glicose hepática para o sangue, sendo a resistência à insulina um fator intensificador desse efeito (Carvalheira, 2002).

Estudos com ovelhas mostram que o tratamento com dexametasona causa alterações na regulação do uso das reservas de glicogênio, elevando a atividade das enzimas glicose-6-fosfatases, relacionadas à utilização de glicogênio, verificado na prole, mas não nas genitoras (Franko et al., 2007). A dexametasona também reduz a expressão de receptores para insulina no fígado, levando a uma incapacidade de importar glicose (Severino et al., 2002). Dessa forma, a análise histoquímica do fígado aponta para uma programação de alteração das reservas de glicogênio hepático nos grupos II e III, reforçando a interferência da dexametasona quando aplicada no terço médio do período gestacional.

\section{CONCLUSÃO}

Os resultados apontam para um efeito tempodependente para a aplicação da dexametasona durante a gestação, levando a alterações temporais distintas no hemograma e na concentração sérica de carboidratos totais nas matrizes e nos primeiros dias de vida da prole.

\section{REFERÊNCIAS}

ALMAWI, W.Y.; LIPMAN, M.L.; STEVENS, A.C. et al. Abrogation of glucocorticoid-mediated inhibition of $\mathrm{T}$ cell proliferation by the synergistic action of IL-1, IL-6, and IFN-gamma. J. Immunol., v.146, p.3523-3527, 1991.

BAUER, A.; TRONCHE, F.; WESSELY, O. et al. The glucocorticoid receptor is required for stress erythropoiesis. Genes Dev., v.13, p.2996-3002, 1999.

BROWN, R.W.; CHAPMAN, K.E.; KOTELEVTSEV, Y. et al. Cloning and production of antisera to human placental 11b-hydroxysteroid dehydrogenase type 2 . Biochem. J., v.313, p.1007-1017, 1996.

CARVALHEIRA, J.B.C.; ZECCHIN, H.G.; SAAD, M.J.A. Vias de sinalização da insulina. Arq. Bras. Endocrinol. Metabol., v.46, p.419-425, 2002.

DHABHAR, F.S.; MCEWEN, B.S. Acute stress enhances while chronic stress suppresses cell-mediated immunity in vivo: a potential role for leukocyte trafficking. Brain Behav. Immun., v.11, p.286-306, 1997.

DHABHAR, F.S.; MILLER, A.H.; MCEWEN, B.S. et al. Effects of stress on immune cell distribution. Dynamics and hormonal mechanisms. J. Immunol., v.154, p.55115527, 1995.

DHABHAR, F.S.; MILLER, A.H.; MCEWEN, B.S. et al. Stress-induced changes in blood leukocyte distribution. Role of adrenal steroid hormones. J. Immunol., v.157, p.1638-1644, 1996.

DIEDERICH; S.; EIGENDORFF, E.; BURKHARDT, P. et al. 11ß-hydroxysteroid dehydroganase types 1 and 2: A important pharmacokinetic determinant for the activity of synthetic mineralo and glucocorticoids. J. Clin. Endocrynol. Metabol., v.87, p.5695-5701, 2002. 
ERICSSON, A.; SÄLJÖ, K.; SJÖSTRAND, E. et al. Brief hyperglycaemia in the early pregnant rat increases fetal weight at term by stimulating placental growth and affecting placental nutrient transport. J. Physiol., v.581, p.1323-1332, 2007.

FAAS, M.M.; SLOT, K.; KOITER, T.R. et al. Corticosterone treatment of pregnant low dose endotoxintreated rats: inhibition of the inflammatory response. Am. J. Reprod. Immunol., v.44, p.178-183, 2000.

FRANKO, K.L.; GIUSSANI, D.A.; FORHEAD, A.J. et $a l$. Effects of dexamethasone on the glucogenic capacity of fetal, pregnant, and non-pregnant adult sheep. $J$. Endocrinol., v.192, p.67-73, 2007.

GIGLIO, M.J; ALIPPI, R.M.; BOZZINI, C.E. Inhibition by dexamethasone of erythropoietin-induced amplification of the erythropoietin-responsive cell compartment. Exp. Hematol., v.9, p.444-448, 1981.

HAYNESWORTH, S.E., BABER, M.A., CAPLAN, A.I. Cytokine expression by human marrow-derived mesenchymal progenitor cells in vitro: effects of dexamethasone and IL-1. J. Cell Physiol., v.166, p.585592, 1996.

HOLNESS, M.J.; SUGDEN, M.C. Glucoregulation during progressive starvation in late pregnancy in the rat. Am. J. Physiol. Endocrinol. Metabol., v.272, p.E556E561, 1997.

HOLNESS, M.J.; SUGDEN, M.C. Dexamethasone during late gestation exacerbates peripheral insulin resistance and selectively targets glucose-sensitive functions in $\beta$ cell and liver. Endocrinology, v.142, p.3742-3748, 2001.

ISBISTER, J.P. Physiology and pathophysiology of blood volume regulation. Transfus. Sci., v.18, p.409-423, 1997.

ISERN, J.; FRASER, S.T.; HE, Z. et al. The fetal liver is a niche for maturation of primitive erythroid cells. PNAS, v.105, p.6662-6667, 2008.

JANSSON, T.; POWELL, T.L. Human placental transport in altered fetal growth: does the placenta function as a nutrient sensor? - A review. Placenta, v.27, p.S91-S96, 2006.

KAHN, S.E.; PRIGEON, R.L.; SCHWARTZ, R.S. et al. Obesity, body fat distribution, insulin sensitivity and islet beta-cell function as explanations for metabolic diversity. J. Neurochem., v.131, p.354S-360S, 2001.

LAURENTINI, A.; EDWARDS C.A. A microtiter modification of the anthrone-sulfuric acid colorimetric assay for glucose-based carbohydrates. Anal. Biochem., v.315, p.413-415, 2003.
MENEGUEL, J.F.; GUINSBURG, R.; MIYOSHI, M.H. et al.; Corticosteroide Antenatal: Ciclo único versus múltiplo - Comparação de Resultados. RBGO., v.24, p. 505-510, 2002.

MOR, F.; COHEN, I.R. IL-2 rescues antigen-specific T cells from radiation or dexamethasone-induced apoptosis. Correlation with induction of Bcl-2. J. Immunol., v.156, p.515-522, 1996.

NYIRENDA, M.J.; LINDSAY, R.S.; KENYON, C.J. et al. Glucocorticoid exposure in late gestation permanently programs rat hepatic phosphoenolpyruvate carboxykinase and glucocorticoid receptor expression and causes glucose intolerance in adult offspring. J. Clin. Invest., v.101, p.2174-2181, 1998.

PENICAUD, L.; FERRE, P.; KANDE, J. et al. Effect of anesthesia on glucose production and utilization in rats. Am. J. Physiol. Endocrinol. Metabol., v.252, p.E365E369, 1987.

ROSA, P.C.S.; PEIRÓ, J.R.; CAMPEBELL, R.S. et al. Efeitos do diclofenaco e da dexametasona na endotoxemia experimenatal em equinos. Arq. Bras. Med. Vet. Zootec., v.55, p.279-286, 2003.

RUGINSK, S.G.; OLIVEIRA, F.R.; MARGATHO, L.O. et al. Glucocorticoid modulation of neuronal activity and hormone secretion induced by blood volume expansion. Exp. Neurol., v.206, p.192-200, 2007.

SEVERINO, C.; BRIZZI, P; SOLINAS, A. et al. Lowdose dexamethasone in the rat: a model to study insulin resistance. Am. J. Physiol. Endocrinol. Metabol., v.283, p.E367-E373, 2002.

SLOBODA, D.M.; CHALLIS, J.R.; MOSS, T.J. et al. Synthetic glucocorticoids: antenatal administration and long-term implications. Curr. Pharm. Des., v.11, p.14591472, 2005.

VEENSTRA VAN NIEUWENHOVEN, A.L.; BOUMAN, A.; MOES, H. et al. Cytokine production by NK-cells as well as by lymphocytes in pregnant women as compared with women in the follicular phase of the ovarian cycle. Fertil. Steril., v.77, p.1032-1037, 2002.

VILAÇA JÚNIOR, P.E.A.; TEIXEIRA, A.A.C.; WANDERLEY-TEIXEIRA, V. et al. Morphological analysis of neonates of rats treated with dexamethasone in the initial phase of pregnancy. Int. J. Morphol., v.26, p.523-527, 2008.

WADDELL, B.J.; BENEDIKTSSON, R.; BROWN, R.W. et al. Tissue-specific messenger ribonucleic acid expression of 11b-hydroxysteroid dehydrogenase types 1 and 2 and the glucocorticoid receptor within rat placenta suggests exquisite local control of glucocorticoid action. Endocrinology, v.139, p.1517-1523, 1998. 